\title{
Chapter 2 \\ Gendered Migrations and Conceptual Approaches: Theorising and Researching Mobilities
}

\subsection{Shifting Analytical Parameters: From Women to Gender in Contemporary Migration Studies}

While the repetitive rhetoric of 'discovering' women as active agents in mobility decisions, plans and the execution of such, might have had a major contribution in filling an important lacuna in migration studies literature several decades ago now (Morokvasic, 1984; Kofman, 1999), there are a number of analytical problems with continuing claims that seem to either conflate 'gender' with women or tend to nearly essentialise the 'feminization of migration' in reflecting discursive stereotypes. In the latter case, gendered migration research requires taking on board the historicity and local embeddedness of particular case studies which should clearly frame sociopolitical and development strategies when conducting studies to understand women migrants and female migration (Cornwall et al., 2008; Dannecker \& Sieveking, 2009; Amelina \& Lutz, 2019). This perspective becomes clear in the following sections and in the box included in this chapter where we include exemplifications from case studies and our own research findings.

The dominating portrayal has been that of international migrants as young males crossing borders primarily consciously for livelihood reasons, either through documented or undocumented means. Yet, even recently through protracted displacement we continue to realise that there is a clear need as migration researchers to generate more disaggregated data by gender, age and family status as to reflect the complexity of vulnerabilities, mobilities and gendered findings (Kofman, 2019). The notion of the popular, but at the same time quite traditional, representation of international migration viewing female migrants as members of family mobilities in the diasporic sense and by extension as more passive followers than active agents in the global mobility phenomenon, along with victimisation discourses in the migrant sex worker industry (Agustin, 2007), has obscured a wider awareness of the autonomy and subjectivities of women migrants. The lack of such awareness of the complexities and intricacies of the historicity of countries of origin and 
destination as well as the embeddedness of social, temporal and biographical parameters (Christou \& Michail, 2019) is an added element to why the 'feminization' of the 'age of migration' can appear as an over-inflated generalisation.

Conceptually, for almost three decades (Braidotti, 1992; Altamirano, 1997; Silvey, 2004; Nawyn, 2010) feminist theories have increasingly highlighted their developments and contributions to migration research. Two decades ago, Kofman still exclaimed that: 'Methodologically, we are more equipped than ever to probe the temporal and geographical complexities of individual, household and group itineraries. There no longer is any excuse for the gender blindness of European mainstream research' (1999: 289). And, in the 2000s and currently, migration scholarship now accepts that mobilities are gendered phenomena which by extension require more sophisticated analytical and theoretical tools than 'studies of sex roles and of sex as a dichotomous variable allowed in the past' (Donato et al., 2006: 4).

Such a sophisticated and more complex set of tools mirrors what Mahler and Pessar (2001) term as a 'gendered geographies of power' approach which links the interconnectedness of the temporal, spatial, scaler, biographical and other intersections on the individual and family level in shaping experiences. Gendered power should be seen as a core catalyst to unravel our understanding of those individual and collective experiences. Migration as a gendered and gendering process is an important realisation for research into the civil, social and political rights of migrants in any destination society (Szczepaniková, 2006). Gendering perceptions are also characteristic of sustaining hegemonic representations of 'white male breadwinner' categories in the post-war (Western) European context despite migrant women filling in important labour market gaps where local origin women would have otherwise been expected to take on (Kofman et al., 2000: 136).

Following Parreñas (2009), in our interrogation of how gender is constituted in migration studies there is a lack of emphasis on gender as a relation of inequality between women and men, and, thus our research should not solely be pointing to differences in femininities and masculinities. That is, in the study of migratory processes it is important that we understand the gendering of such as the study of the emergence of inequalities among women and men migrants. More importantly, it is crucial that discussions on gendered migration continue to explore the gendered experiences of men migrants, especially their vulnerabilities, marginalisations, affective channels, personal and family ties in a nuanced approach which embraces critical insights of their inequalities (Pasura \& Christou, 2018). The invisibility of the migrant man while reduced in recent literature (Charsley \& Wray, 2015), still requires a holistic approach to understanding migration trajectories in tandem with structures impacting migrant identities and life stories, the nuances of migrant agency, the complexity of societal spheres, familial, personal and social relationships. As Wojnicka and Pustułka (2019: 91) assert, 'migration as a process influences the changes in defining, negotiating and performing masculinities, while male migrants create a myriad of migration forms. Stating that migration is a gendered and gendering process has conspicuous consequences for men, women and societies, with the notion of migrants' sex preconditioning our reception of migratory flows'. At the same time, it is crucial to underscore that 'migrant men' should not be 
conflated into a unified homogeneous group as parameters of intersections and/or the matrices of age, generation, class, race, ethnicity, sexuality, ability, etc. are all generative of multidimensional outcomes for male migrant trajectories and their positionalities within given societies. Added to these are the usual translocal and transnational layers that might also shape their mobilities and identities in host and home countries. In this direction, we see an intersectional and holistic approach to the study of migrant masculinities as being an alternative conceptualisation to the more insular view on 'hegemonic masculinity' (Christou, 2016a).

Transnational approaches to migrant masculinities also deepen understandings of how gendered migrations are constituted and how identities might be reconfigured in the process. In such a process, new forms of hybrid masculinities might emerge and so they are also socially constructed, fluid and transformative. Migrant masculinities can also become translatable to otherwise patriarchal hegemonic versions when men are on the move (Datta et al., 2009; Pasura \& Christou, 2018) but also in the messiness of everyday life where identities are constantly reshaped by experiential means (Noble, 2009). Ultimately, components of dysfunctional practices in social and familial relations can bring into conversation the public and private spheres where migrant masculinity can be further shaped by struggles, contradictions and power impacts. The crafting of migrant masculinities is also contingent to the aesthetic labour and reproductive labour demands that shape how they are constructed as gendered subjectivities (Warren, 2016; Fiałkowska, 2019; Gallo \& Scrinzi, 2019).

Recent research on immigrant men has also sought to bring them back into the analytical frame 'not as androcentric agents, but as actors with gendered, intersectional social locations imbued with both masculine privilege and social marginality' (Hondagneu-Sotelo, 2017: 112). Migrant men thus can be recipients of the empowerment that masculine privilege brings while at the same time they can be racialised and marginalised when their working class ethnicised status intersects with regimes of social and labour geographies that allow for new hierarchies to emerge. This leads to exciting new theorisations drawing from a Bourdieusian lens on 'ethnic habitus' in how marginalised groups 'construct and perform situated dominant masculinity' (Grosswirth Kachtan, 2019: 1489). Such research demonstrates that in particular ethnocultural settings performances of 'worthy dominant masculinity' leads to the exposure of a separation between social and masculine status thus unveiling masculinities as performative, relational and contextual social practices in specific settings (ibid).

Male migrant masculinity and agency can also be viewed through a feminist lens to analyse the complexities of gendered mobility, familial and gender relationships. Choi (2019) proposes the concept of 'masculine compromise' to explore the material impacts on gender practices within family life, gender identity and gender attitudes. Additional research by Vlase (2018: 195) on men migrant subjectivities reveals how migration not only deeply shapes but extensively transforms masculinities often threatened by life events, lack or complexity of life milestones and other social encounters which prompts migrants to 'discursively resecure their sense of 
adult-male status by framing their experiences transnationally, in a broader sociocultural context of both home and host countries'. Discursive and experiential accounts of migrant masculinities point to their malleable aspect but this should not been seen as devoid of agency, conscious planning and individual reconfiguration.

\subsection{Intersectionalities and Conceptual Approaches in Researching Gendered Social Transformations}

The shift from women to gender in migration studies has also seen the opening toward a more generative and intersectional approach to the research on contemporary gendered mobilities (Näre \& Akhtar, 2014). The incorporation of multiple categories relevant to the understanding of intersectional hierarchies can unveil inequalities, relationships and meanings in migration that can inform how gendered identities and roles emerge as shaped by social reproduction, class division, generation and other institutional and structural practices.

Such analytical gaps make the more intersectionally theorised works compelling in providing wider insights into social categories, hierarchies and inequalities (Bastia, 2011; Grosfoguel et al., 2015). More specifically, significant contributions on intersectionality in migration studies have reflected on how we theorise through a 'translocational lens' (Anthias, 2020) in order to address the connections between social divisions and identities and to understand hierarchies/inequalities through modalities of relational, processual and spatio-temporal instances of power.

In explaining the origins of 'intersectionality' and its meaning, it is Kimberlé Crenshaw, a law professor at Columbia University and UCLA who coined the term 'intersectionality' more than three decades ago (1989) to describe the way people's social identities can overlap in instances of inequality and discrimination. The concept has triggered heated debates in academic and public discourse, frequently has been misused in its application to research and theorising, has led to the politicization of the idea, as well as a lasting relevance and re-visiting of its parameters in affirming that inequalities are indeed multidimensional and not uniform.

So, if we aim to condense intersectionality into a succinct definition, we can say that it is an analytic framework that attempts to understand and transcend how interlocking systems of power, oppression and privilege interact, and specifically to address through this lens their combined impact on those who are marginalised and disempowered within a given society.

At its crux, intersectionality theory asserts that multiple forms of oppression, such as those relating to gender, class, ethnicity, race, sexual orientation, disability, age, generation, etc. are not experienced separately, but interact upon and reinforce each other. 
In feminist scholarship, intersectionality has been accepted as an approach of major significance to inclusive research while also being criticized as ambiguous (Bilge, 2013; Davis, 2008). The conflation of intersectionality as a theory, a methodological approach and an activist application has further weakened its robustness and these three aspects require disentangling (Bürkner, 2012). By focusing on the axes of social divisions and categorisations in a dynamic way we can locate the experiences of those marginalised and excluded by framing through key multidimensional structural oppressions.

Moreover, it is important to acknowledge that only quite recently we find more critical conversations in the academic literature combining queer migration theorisations with sexual citizenship studies and wider human rights based approaches in the gender and sexuality areas of research (Lewis \& Naples, 2014; Luibhéid, 2018). Such a conceptual approach makes a major twofold contribution to migration studies: by enhancing the visibility of LGBTQI+ migrants, refugees and asylum seekers (see also Chap. 5) within a combined rights and sexual citizenship rights context, and that we also expand a critical engagement of those intersections of sexuality, gender, culture and migration in challenging essentialisations 'in individual expressions of desire and identity and border politics more generally' (ibid: 911). That is, in queering the transnational political economies of mobilities of scale we highlight queer social movements politics and multiscalar citizenship practices (Grundy \& Smith, 2005; Lewis, 2013).

\section{Box: Queer Theory}

Queer theory emerged in the 1990s from two different stands, the poststructuralist thought of Judith Butler, and lesbian and gay politics. Queer theory problematises assumptions of identity politics that sexuality constitutes a stable identity which informs specific lesbian and gay lifestyles, practices and cultural expressions. Queering renders fluid the categories of sexualities and genders and underscores the artificiality of boundaries. More importantly, it gives visibility to any hierarchical division of particular categories of desires, sexual practices and the intimacy of social subjects, frequently excluded as 'dissident' or 'other'. 'Queer' rather stands against homogenizing and contests normativity, whether such practices descend from hegemonic heterosexual discourses or from mainstream lesbian and gay politics in the framing of identities as sites of 'becoming' and questioning of norms. As a result, in migration studies we might consider a 'queer' approach to research, as a distinct methodological approach that aims to perform an act of 'queering', to de-naturalise taken for granted categories of analysis, even beyond issues of sexuality and gender.

Queer theory in migration studies has been applied as a distinct methodological approach to the study of mobility themes shaped by gender and sexuality in seeking to denaturalise categories of analysis and to make 
normativity visible. The implications for queer migration scholarship are new opportunities to develop the field in interrogating the politics of queer mobilities, the ambivalent spatialities where these might emerge, the fragmented contexts of diverse societies for queer inclusion and the challenging of border regimes, normative and state violence, racial capitalisms and the carceral geographies of bordering as well as the carceral spectacle of suffering of detention centres and refugee camps.

Queer migration scholarship critically engages heteronormative as well as homonormative arrangements of borders, bodies, desires and movements shaped by the bureaucratic institutions of the neo-liberal nation-state and capitalist discourses (Murray, 2014). While sexualities issues are at the centre of these discourses, interconnections with other intersectional categories and their resulting oppressions, exclusions and marginalisations experienced by mobile social actors such as migrants, refugees, returnees and asylum seekers, are the articulations of such encounters. This is because processes of movement and belonging are amalgamated with dynamics of institutions and social relations where intersectional inequalities emerge. These are analytical opportunities for 'queer intersections' to be further investigated (cf. Manalansan, 2006). For instance, queering migrant representations despite elements of contestation and ambivalence can offer a new repertoire of how queer subjectivities and socialiaties emerge and are reconfigured along fixed notions of 'nationhood' and 'citizenship'. These are important conversations that we need to have and even more critically imperative research that needs to be undertaken to inform policy countering a dangerous mixture of xenophobia, homonationalism, transborder transphobias and toxic binaries of othering difference.

For more information see the open access book volume on 'Queer Migration and Asylum in Europe' edited by Richard Mole (2021) here:

https://www.uclpress.co.uk/products/141641\#

On an individual basis, otherwise repressed (non-heteronormative) sexualities and the re-negotiation of ageing masculinities involves a disruption of identities constructed during (return) mobilities that requires deconstructing power relations shaped by ethnonational signifiers (Christou, 2016a). In exploring such gendered personal and social transformations it is important to keep in mind the tensions that might intersect when structural, individual and cultural parameters collide with respect to affective and gendered meanings of migrant identities. Methodologically, hermeneutical phenomenological analyses on empirically grounded studies can address the multiple layers of power in transnational gender relations (ibid). Moreover, since sexual normativity is a core exemplification of power and exclusion, it is revealing to acknowledge the provocation by Carastathis and Tsilimpounidi (2018: 1120-1121) about the 'omnipresence of methodological heteronormativity in the (visual) discourse surrounding the declared "refugee crisis", (see Chap. 5). They 
assert: 'All migration politics is reproductive politics. The nation-state project of controlling migration secures the racialised demographics of the nation, understood as a reproducible fact of the social and human body, determining who is differentially included, who is excluded, and who is exalted. Citizenship, illegality, and asylum are often affirmed or rejected as inheritable transitive properties that adhere to a person by virtue of heteronormative (or, more rarely, homonormative) configurations of kinship' (ibid).

As a theoretical and methodological approach to migration research, intersectionality draws on the relationality within social contexts of migrancy, power and inequalities, thus drawing out the complexity of mutually constitutive forms of oppression. Critical social geographers continue to advocate for more inclusion of black feminist intersectional perspectives and for an ethically-driven care of its application. This is so it does not reproduce inadvertently white, masculinist, racist and colonialist perspectives including foci on transnational migration and embodiment (Hopkins, 2019).

Critical theorising in this direction can also surpass the impasse of embracing the political implications of migration as emergent of migrant agency. Such an approach is articulated in a theoretically motivated recent piece by Jonsson (2020) in underscoring the profound political implications of ongoing conceptual turns and methodological shifts combining 'borders' and 'agency' while analysing the interconnections of these theoretical contexts. Namely, this piece by Jonsson highlights that the legacies of colonialism and the significance of protest as political agency are intrinsic to the realisation of democracy and should not be ignored in European societies and histories when it comes to migration.

The importance of intersectionality as an analytical framework in migration studies generates an inclusive understanding of migrants as members of multiple (under/privileged) groups and the barriers they might face. These intersections underscore the inequalities of interconnectedness at a personal and systemic global level. While migration has been theoretically placed within approaches that embrace a broad range of sociocultural, transnational and translocal social fields (Anthias, 2012), one of the frequently missing social categories examined has been consistently 'class' in the corpus of literature on the gendered geographies of mobilities (Kofman, 2004; Cederberg, 2017; Fresnoza-Flot, 2017). Class, is quite often, a neglected social signifier in intersectional analyses, yet, its inclusion fills important gaps in integrating social stratification for a more nuanced intersectional analysis of migrant experiences and positionalities (e.g. Anthias, 2012). A Bourdieusian analysis of class and migration has been prominent in migration studies (Erel, 2010; Oliver \& O'Reilly, 2010; also see Chap. 3) and class has historically been a significant social categorisation in the study of gendered understandings of migrant ethnicity (Anthias, 1992).

Unlike research about marginalised and underprivileged groups, Mastoureh Fathi's (2017) research, drawing on intersectionality and class analyses of narratives of Iranian women migrants in the UK, focuses on the social positions of highly skilled professional migrant women who as medics grapple with class subjectivities, social location performativities and social hierarchies. These interconnections point 
to the complexity of othering processes especially in the interplay of gender, class and racializations which tend to operate in contradictory and multiple ways. This is intriguing since intersectional studies concerning the treatment of more privileged groups has been by and large disregarded. The study reveals two crucial components of intersectional class: the persistence and importance of power relations on the one hand and the performative legitimacy of belonging in varying social fields.

Issues of power and belonging are also linked to how intersectionality can easily become 'depoliticised' in the direction that Erel et al. (2010) conceptualise multiple oppressions in critical sexuality studies. Their work highlights the often neglected exclusionary effects of the concept and in particular transgender and transsexuality queer discourse. The authors contend that intersectionality has conceptually failed in crafting progressive impulses within the multiculturalism debate and as a result there are methodological implications that point to interconnected webs of power and hierarchies.

In the next section we inform this discussion with further insights on key conceptual turns in migration studies. This section is not meant to be exhaustive in providing an inventory of central conceptual trends and directions in migration studies, but rather it aims to highlight some of the key turning points that shaped its trajectory over the past three decades. This sets the scene for further reflective insights in the final section on theoretical, methodological and ethical issues of significance in research concerning gendered mobilities.

\subsection{Key Conceptual Turns in Migration Studies}

The study of gender and migration has historically seen the entire migration process perceived as a gendered phenomenon, across a variety of spatial and temporal scales and various intersections of individual and family cycles, biographical, historical and national time, the politics and governance of states and capitalist world systems (Donato et al., 2006). Such research insights of gender and migration have not only strengthened the interdisciplinary field of migration studies but have also theorised new research approaches and strategies from qualitative, quantitative and mixed methodological perspectives. In this section we outline some of the key conceptual turns in migration studies, make links to the gendered layers of these, or lack thereof, and, reflect on methodological and ethical issues.

In their historical tour of methodological nationalism Wimmer and Glick Schiller $(2002,2003)$ contend that the shift towards the study of 'transnational communities' is the last historical conceptualisation in post-war social sciences entering the study of migration. This occurring, as they explain in detail in their 2002 and 2003 joint articles, as an epistemic move to disconnect from methodological nationalism rather than an embrace of new objects of observation for migration studies scholars. Since Chap. 4 discusses key parameters of the transnational approach, here, we only highlight the impetus toward this conceptualisation and the diversions from there to other approaches. 
One of the approaches going beyond methodological nationalism according to Biao Xiang's (2016) 'epistemological behaviouralism', might on the one hand, redress the limitation of taking the nation-state as pre-given container of social life for migrants in erasing the conceptual divide that internal and international create, on the other, it creates new problematic thinking in 'behaviouralizng' the migration phenomenon. Remarkably, Xiang addresses both conceptual limitations by interlinking them as 'constituted and constitutive assemblages' (ibid: 669) and while reconfigured by mobilities as an analytical perspective to explore broader social changes.

Another recent call recognising the need to go beyond methodological nationalism (and multiculturalism) to identify epistemological approaches to produce new migration knowledge is that of 'methodological interculturalism' as argued by Zapata-Barrero (2019). The core recognition here is the unit of analysis being 'diversity' itself rather than the migrant, the state, the nation or any other lens that does not take a diverse public culture of justice approach linked to solidarity and cosmopolitanism as its core analytical framing. In this sense, methodological interculturalism aligns well with research foci on race and discrimination and wider migration policy research driven by an anti-racist, equity, justice and solidarity agenda. In other words, it aligns with analytical frameworks that focus on unveiling power and exclusion while putting forward policy agendas embracing diverse, just and equitable societies.

Theoretical constructions of migration pose both epistemological and ethical problems that correlate with methodological nationalism. According to Anderson (2019) the two paradigm shifts of the mobilities turn and methodological transnationalism have been highly generative and that is why Anderson builds on critiques and alternatives in proposing an approach Anderson terms 'methodological denationalism'. This particular conceptualisation builds on a clear distinction: that of 'migrant' and 'citizen' in 'migrantizing the citizen' in understanding exclusions of 'non-citizenship'. Anderson (ibid) draws attention to how global, regional and local institutions and processes impact on the migrant/citizen in underscoring the sensibilities of historicising concepts, theories and practices informing research. Anderson suggests that, "in this way it has the potential to recover relationalities and interdependence to shed light on the impacts of methodological nationalism beyond the academy and into politics' (p. 7). The latter is the core objective of an approach that migrantizes the citizen as Anderson contends it will enable research to make connections between formal and informal exclusions which are often multiple and go beyond citizenship.

Exclusions and belongings have figured in a variety of conceptual turns but that of the cultural and materialities approach to migration studies has sought to engage with migrant cultures from a material, embodied and identities perspective. The latter do not overlap but find an impetus in how culture and cultural geographies of migration (e.g. cultural and diasporic landscapes, see Christou \& King, 2010) can trigger paradigmatic trends in examining the materialities and emotionalities of migration (Christou \& Janta, 2019), the affectivities of embodied mobilities (Christou, 2011; Christou \& King, 2011), and, how these can shape identities 
(King \& Christou, 2010). Basu and Coleman (2008) utilised early on the term 'migrant worlds' to firstly acknowledge the materiality of migration, secondly the material consequences of mobilities and thirdly the interconnections of movements of objects and migrants simultaneously. This last third point referring to the binaries and divides between people and things is considered to be one of the biggest 'blind spots' that prevents 'from seeing the full picture and complexity of migration trajectories and pursuit' (Wang, 2016: 2).

These are all phenomenological insights to material and migrant cultures in the study of place-making, identity construction and meaning making in how migrants interact with the world surrounding them, the stuff surrounding them and how sensorial reactions emerge in the mundane experiences of mobile lives. Migrant embodied and sensorial engagements with the materialities of their transnational worlds happen through emotions, living, consuming, interacting with others and objects. Some of these aspects are linked to consumption and lifestyle. As previously, it is important to explore how such experiences and stories of migrant gendered narratives in a psychosocial intersectional perspective articulate implications for gendered migrations (Phoenix \& Bauer, 2012).

Further recent conceptualisations include that of the concept of 'lifestyle migration' which Benson and O'Reilly (2016) closely consider in capturing its application as analytical tool and alternative way to thinking about mobilities. Operationalising 'lifestyle migration' points to synergies of movements as practices and how they are understood as meanings in the sociological imagination, including aspiration and the processes that situate them. It is a vibrant field of research which over the years has examined a range of groups and destinations reflecting the definition of lifestyle migration as the movement of 'relatively affluent individuals, moving either parttime or full-time, permanently or temporarily, to places which, for various reasons, signify for the migrants something loosely defined as quality of life' (Benson \& O'Reilly, 2009: 621). As a conceptual approach, 'lifestyle migration' can be seen as a driver of migration (or return), having a direct impact in shaping post-movement living and the longer-term implications of settlement and integration as these processes unfold over time. The approach extends beyond the economic and political parameters in shaping the kinds of lives that migrants imagine, experience, plan and dream. This for example has implications in recent calls to problematise the theoretical underpinnings of lifestyle migration and to critically examine the conceptual construction of lifestyle migrants. Recent research has initiated a response to this call by demonstrating how social hierarchies add a depth of dimensions such as class, gender and sexuality interconnected to prisms of 'cosmopolitanism' (Dixon, 2020).

There is an implication of agency here in the imagination of lifestyles but these should not be romanticised in stripping away the impacts of the social geographies, social structures and social constructions which are a part of mobile lives. For instance, lifestyle mobilities can become 'discordant' (Botterill, 2017) when material challenges can lead to a sense of emotional entrapment and immobility when practices, state policy, economic constraints and other insecurities can curtail freedom and destabilise initial enthusiasm. Such outcomes directly point to the relational framing of this conceptual approach in situating the experiential aspects of 
particular case studies and understanding that migrant agency can be confronted by wider structures during the mobility and settlement process. Indeed, we can talk about the intersections of the mobilities paradigm with movement and lifestyle choice as 'lifestyle mobilities' (Cohen et al., 2015) in grasping the complexities of migration, leisure and travel. We understand that the corporeality of mobility cannot be easily deconstructed in the traditional binaries of work and leisure, home and away, place and movement, lifestyle and identity. All these patterns of movement and living can become enmeshed or uncoupled as defining avenues to research lifestyle mobilities.

Another key 'turn' being recently re-visited in migration studies is that of the reflexive turn. Its emergence in the social sciences and humanities during the 1980s, especially within ethnographic methodologies and stemming from critical theory and feminist politics and philosophy shaped much thinking in textual, social and cultural theory about the production of knowledge. The complex entanglements of knowledge production along with the 'tyranny of categories' (Stewart, 2015) and multiple contestations emerging in decolonial thought recently has posed renewed challenges to migration scholars to question epistemic communities (see Kofman, 2020 for a current intervention on gender and migration). Concomitantly, others have recently argued that reflexivity among research participants should be incorporated in a renewed definition of reflexivity as mutually constitutive by both researchers and research participants in the co-construction of knowledge (Dahinden et al., 2020). Amelina (2020) also inspired by the reflexive turn, underscores the need to develop a 'doing migration approach' that will embrace mobility, immobility and intersectionalities in discursive knowledge and other configurations in practices which are generative of social orders of migration and how we situate migrants conceptually. Amelina sees potential in this analytical approach as being beyond reflexive and 'doing' migration which leads to a conceptualisation of a social production of the migrant in paying attention to performativities of routines, knowledge and power involved in these processes. This clearly connects with the earlier 'gendered geographies of power' approach advanced by Mahler and Pessar (2001) two decades ago in understanding how a gendered optic in transnational mobilities plays a crucial role in the creation, transformation and fortification of transnational social spaces.

In the next section we round up this discussion with further insights on issues of power and hierarchies in research on gendered mobilities highlighting theoretical, methodological and ethical considerations.

\subsection{Tackling Theoretical, Methodological and Ethical Issues in Research on Gendered Mobilities}

Migration as a phenomenon and its topical themes have been researched from a variety of humanities and social science disciplines (sociology, geography, economics, demography, anthropology, media and film studies, cultural and literary studies, 
etc.) through multi-method approaches in investigating regional, urban, suburban and rural locations, primarily dominated by a focus in the Global North with some recent explanatory shifts to the Global South and through a number of schools of thought.

Migration studies has benefited from interdisciplinary explorations with qualitative, quantitative, mixed methods, ethnographic, digital and other tools integrated in small and large-scale single case study or comparative studies. It appears that the sky is the limit in studying mobilities, with generations now of trained migration scholars at the postgraduate and doctoral level at a burgeoning number of academic programmes and through a flourishing of funded studies globally.

It is undeniable that migration studies has developed in multi-faceted directions over a number of decades, incorporating different thematic and topical foci, conceptualisations and methodological directions. The shift to acknowledging the Global South as an important angle in the knowledge production within mobility studies (Fiddian-Qasmiyeh, 2020) has been important and, so has, as mentioned previously, the gendered, feminist and queer lens. What a recent mapping of migration studies, through an empirical analysis of the research field, shows is that a recovery of topical connectedness points to a 'theoretical and conceptual coming of age of migration studies' (Pisarevskaya et al., 2019: 1).

Indeed, pushing the boundaries in liberating our analyses from concepts and instead leaping to the realisation that conceptual heuristic devices might probably be 'impositions' as perhaps the body of scholarship of migration studies is itself, can be frightening but also freeing analytically. For one, freedom from clearly defined conceptual devices can possibly become a productive immersion into new theoretical terrains in the tradition of grounded theory often misused and misunderstood in research. Such an inductive approach enables researchers to seek out and conceptualise social phenomena through processes of interpretative and comparative deconstructing of data.

Yet, it is important to acknowledge existing conceptual and theoretical boundaries and not conflate them unnecessarily. For instance, we would disagree with Stephanie Nawyn's (2010: 749-750) assertion stating that: 'Because most people studying gender and migration use a feminist analytic lens, feminist methods, I often refer to gender and migration scholars as feminist migration scholars'. We would avoid such a conflation of gender with feminist approaches as one does not pre-suppose the use of the other. So, for instance, while in studies of diasporas, tourism mobilities, youth migrants, and masculinities we encounter a feminist lens in researching gendered issues (Christou, 2016a, b; Pasura \& Christou, 2018; Janta \& Christou, 2019), in others we clearly do not see feminist theorisations in analysing gender (Kanaiaupuni, 2000; Liversage, 2009; King et al., 2013). Hence, it might appear self-explanatory, but obviously it is not, so remains important to avoid fixed assumptions that, either gendered migration research refers to women only or that gendered migration research is at the same time feminist in its approach, methods and conceptualisation. 
As migration is a phenomenon deeply connected to relationships, emotions, experiences, etc. of the lived experience, biographical, narrative and life history methods are a means of capturing the complex, multi-layered and nuanced understandings of migrant lives. The migrant life story can become a way to learn from in how wider issues of social policy can be addressed. This is equally important in social policy research with refugees and asylum seekers where biographical methods can expand the theorising and understanding of asylum (O'Neill \& Harindranath, 2006). Narrative inquiry is a means by which we systematically gather, analyse, and represent migrant stories as told by migrants themselves, which challenges more traditional and modernist views of truth, reality, knowledge and personhood. Subjective meanings and a sense of self and identity are negotiated as the stories unfold, bearing in mind that stories are re/constructions of the migrant experience, remembered and told at a particular point in migrants' lives, to a particular researcher and for a particular purpose.

This all has a bearing on how the stories are told, which stories are told and how they are presented and interpreted. They do not represent 'life as lived' but our representations of those lives as told to us. Hence, stories can be viewed as socially situated knowledge constructions in their own right that value messiness, difference, depth and texture of experiential life. In narrative analysis the emphasis is on co-construction of meaning between the researcher and participants. As researchers while being involved in listening we are in a sense 'translating' the conversations. Researchers take in what is being said and compare it with their personal understandings, without filling in any gaps in understanding with 'grand narratives', but rather inquiring about how pieces of the stories make sense together. The process of 'data gathering' and 'analysis' therefore becomes a single harmonious and organic process.

Recent theoretical dialogues on migration in China (Zhu \& Qian, 2020) highlight migrant identity and subjectivity as an evolving process of reconstruction shaped by scales, spaces, encounters, interactions and practices unfolding in everyday experiences where 'the purpose of highlighting banality and everydayness is beyond merely providing thick descriptions of migratory experiences but to demonstrate that proper conceptualisations of migration must exceed pure economic reason or a singular rationality. Migration is always complicated by needs, aspirations, interests and pursuits that are situated, unpredictable and contingent on the immediate milieus of movement and encounter. Whether migrants have resources and abilities to adapt to such contingencies affect their wellbeing in profound ways' (ibid 13-14). These processual approaches give insight to subjective nuances which are revealing of migrant life stories and there has been a rich and prolific literature in this domain (Eastmond, 2007; Gómez-Estern \& de la Mata Benítez, 2013; Fathi, 2017; Baran, 2018).

Stories of mobility can also be stories of trauma, displacement and exclusion culminating in recent years in a proliferation of new research in this area linked to wider geopolitical developments in the last decade. In this context, migrant children 
and refugee youth have come to be constructed as 'crisis figures' in Europe (Lems et al., 2020) but such a sense of exceptionality can trigger conceptually flawed categorisations that essentialise accompanied minors (see Chap. 5). Any research requires a process of ethical reflexivity but research with vulnerable populations raises several ethical questions in upholding research integrity (Akesson et al., 2018). Ethnographically driven research with such populations can focus on how research participants make sense of some of the ascriptions and social categorisations applied to them.

It is important to note that research with unaccompanied youth also illustrates that young mobiles are frequently struggling with how the ambiguity of their refugee figurations are portrayed as 'deserving' or 'undeserving' (Wernesjö, 2020). Mobile youth narratives of un/deservingness articulate how they are constituted as social subjects in defending themselves as hard-working, responsible, diligent and not threatening or victimised (ibid). These processes of narration can be seen as 'manifestations of conditional belonging' (ibid: 389) contingent on negotiations of deservingness.

While research into vulnerable migrant groups can be revealing and of particular ethical significance to inform policy and teaching, as researchers we often find that procedural ethics might tend to be overly burdensome, lengthy, irrelevant and, at times paternalistic, when it comes to vulnerable groups. Research taking place in volatile settings following war, disasters, environmental displacement, etc. can trigger much onerous ethical processes which might delay and even hinder research with populations in those areas. In a sense, this is stripping them from a voice to sharing their stories with the rest of the world and hinder more participatory action research or critical ethnographies to be carried out.

An ethical and reflexive approach should inform the entire research process. This begins with obtaining formal institutional approval, subsequently establishing networks and relationships with potential participants and/or gatekeepers to negotiate access, the collection of data, interpretation, analysis, writing and representation. These processes of reflexive ethical practice are akin to micro-ethical perspectives that require researchers being attentive to managing the dis/comfort zones, affective encounters and boundaries to harm (Akesson et al., 2018). Conducting ethical research with migrant populations at large, and more vulnerable in particular, requires adherence to all these procedural and practical safeguarding steps.

Finally, although it has been pointed out repeatedly, the advice of more conscious efforts to decrease the divide between qualitative and quantitative methodologies is beneficial to the field of migration studies in its entirety, but especially in the analysis and theorising of gender in migration studies (Donato et al., 2006). Yet, this remains one of the challenges of furthering analytical approaches of gender and migration, often a tension that could be harnessed in capturing rich insights (see Chap. 5 for the need to disaggregate data by gender and other social divisions) of the situational and relational categories we explored in this chapter. Quantitative data can also be useful in developing comparative perspectives as with the prevalence and types of transnational families and parenting (see Chap. 4). 


\section{References}

Agustin, L. (2007). Sex at the margins: migration, labour markets and the rescue industry. Zed Books.

Akesson, B., Hoffman "Tony", D. A., El Joueidi, S., \& Badawi, D. (2018). "So the world will know our story": Ethical reflections on research with families displaced by war [59 paragraphs]. Forum Qualitative Sozialforschung/Forum: Qualitative Social Research, 19(3), Art. 5. https:// doi.org/10.17169/fqs-19.3.3087

Altamirano, A. T. (1997). Feminist theories and migration research: Making sense in the data feast? Refuge: Canada's Journal on Refugees, 16(4), 4-8.

Amelina, A. (2020). After the reflexive turn in migration studies: Towards the doing migration approach. Population, Space and Place, e2368. https://doi.org/10.1002/psp.2368

Amelina, A., \& Lutz, H. (2019). Gender and migration: Transnational and intersectional prospects. Routledge.

Anderson, B. (2019). New directions in migration studies: Towards methodological de-nationalism. Comparative Migration Studies, 7, 1-13.

Anthias, F. (1992). Ethnicity, class, gender and migration: Greek Cypriots in Britain. Gower.

Anthias, F. (2012). Transnational mobilities, migration research and intersectionality: Towards a translocational frame. Nordic Journal of Migration Research, 2(2), 102-110.

Anthias, F. (2020). Translocational belongings: Intersectional dilemmas and social inequalities. Routledge. https://doi.org/10.4324/9780203730256

Baran, D. (2018). Narratives of migration on Facebook: Belonging and identity among former fellow refugees. Language in Society, 47(2), 245-268.

Bastia, T. (2011). Migration as protest? Negotiating gender, class, and ethnicity in urban Bolivia. Environment and Planning A: Economy and Space, 43(7), 1514-1529.

Basu, P., \& Coleman, S. (2008). Introduction: Migrant worlds, material cultures. Mobilities, 3(3), 313-330.

Benson, M., \& O'Reilly, K. (2009). Migration and the search for a better way of life: A critical exploration of lifestyle migration. The Sociological Review, 57(4), 608-625.

Benson, M., \& O'Reilly, K. (2016). From lifestyle migration to lifestyle in migration: Categories, concepts and ways of thinking. Migration Studies, 4(1), 20-37.

Bilge, S. (2013). Intersectionality undone. Saving intersectionality from feminist intersectionality studies. Du Bois Review: Social Science Research on Race, 10(2), 405-424.

Botterill, K. (2017). Discordant lifestyle mobilities in East Asia: Privilege and precarity of British retirement in Thailand. Population, Space and Place, 23(5), e2011. https://doi.org/10.1002/psp. 2011

Braidotti, R. (1992). The exile, the nomad, and the migrant: Reflections on international feminism. Women's Studies International Forum, 15(1), 7-10.

Bürkner, H.-J. (2012). Intersectionality: How gender studies might inspire the analysis of social inequality among migrants. Population, Space and Place, 18(2), 181-195.

Carastathis, A., \& Tsilimpounidi, M. (2018). Methodological heteronormativity and the "refugee crisis". Feminist Media Studies, 18, 1120-1123.

Cederberg, M. (2017). Social class and international migration: Female migrants' narratives of social mobility and social status. Migration Studies, 5(2), 149-167.

Charsley, K., \& Wray, H. (2015). Introduction: The invisible (migrant) man. Men and Masculinities, 18(4), 403-423.

Choi, S. Y. P. (2019). Migration, masculinity, and family. Journal of Ethnic and Migration Studies, 45(1), 78-94.

Christou, A. (2011). Narrating lives in (e)motion: Embodiment and belongingness in diasporic spaces of home and return. Emotion, Space and Society, 4, 249-257.

Christou, A. (2016a). Ageing masculinities and the nation: Disrupting boundaries of sexualities, mobilities and identities. Gender, Place and Culture: A Journal of Feminist Geography. https:// doi.org/10.1080/0966369X.2015.1058760 
Christou, A. (2016b). 'The wretched of Europe': Greece and the cultural politics of inequality. Humanity and Society. https://doi.org/10.1177/0160597616664169

Christou, A., \& King, R. (2010). Imagining 'home': Diasporic landscapes of the Greek second generation. Geoforum, 41, 638-646.

Christou, A., \& King, R. (2011). Gendering diasporic mobilities and emotionalities in GreekGerman narratives of home, belonging and return. Journal of Mediterranean Studies, 20(2), 283-315.

Christou, A., \& Janta, H. (2019). The significance of things: Objects, emotions and cultural production in migrant women's return visits home. The Sociological Review, 67(3), 654-671.

Christou, A., \& Michail, D. (2019). Post-socialist narratives of being, belonging and becoming: Eastern European women migrants and transformative politics in an era of European crises. New Formations: A Journal of Culture, Theory \& Politics, 17, 70-86.

Cohen, S. A., Duncan, T., \& Thulemark, M. (2015). Lifestyle mobilities: The crossroads of travel, leisure and migration. Mobilities, 10(1), 155-172.

Cornwall, A., Harrison, E., \& Whitehead, A. (Eds.). (2008). Gender myths \& feminist fables. In The struggle for interpretive power in gender and development. Blackwell Publishing.

Crenshaw, K. (1989). Demarginalizing the intersection of race and sex: A black feminist critique of antidiscrimination doctrine, feminist theory, and antiracist politics. University of Chicago Legal Forum, 14, 538-554.

Dahinden, J., Fischer, C., \& Menet, J. (2020). Knowledge production, reflexivity, and the use of categories in migration studies: Tackling challenges in the field. Ethnic and Racial Studies. https://doi.org/10.1080/01419870.2020.1752926

Dannecker, P., \& Sieveking, N. (2009). Gender, migration and development: An analysis of the current discussion on female migrants as development agents. COMCAD Arbeitspapiere Working papers, No. 69. COMCAD - Center on Migration, Citizenship and Development.

Datta, K., McIlwaine, C., Herbert, J., Evans, Y., May, J., \& Wills, J. (2009). Men on the move: Narratives of migration and work among low-paid migrant men in London. Social and Cultural Geography, 10(8), 853-873.

Davis, K. (2008). Intersectionality as buzzword: A sociology of science perspective on what makes a feminist theory successful. Feminist Theory, 9(1), 67-85.

Dixon, L. (2020). Gender, sexuality and lifestyle migration: Exploring the impact of cosmopolitan place-marketing discourses on the post-migratory experiences of British women in Spain. Current Sociology, 68(3), 281-298.

Donato, K. M., Gabaccia, D., Holdaway, J., Manalansan, M., \& Pessar, P. R. (2006). A glass half full? Gender in migration studies. International Migration Review, 40(1), 3-26.

Eastmond, M. (2007). Stories as lived experience: Narratives in forced migration research. Journal of Refugee Studies, 20(2), 248-264.

Erel, U. (2010). Migrating cultural capital: Bourdieu in migration studies. Sociology, 44(4), 642-660.

Erel, U., Haritaworn, J., Rodríguez, E. G., \& Klesse, C. (2010). On the depoliticisation of intersectionality talk: Conceptualising multiple oppressions in critical sexuality studies. In Y. Taylor, S. Hines, \& M. E. Casey (Eds.), Theorizing intersectionality and sexuality (pp. 56-77). Palgrave Macmillan.

Fathi, M. (2017). Intersectionality, class and migration: Narratives of Iranian women migrants in the U.K. Palgrave Macmillan.

Fiałkowska, K. (2019). Remote fatherhood and visiting husbands: Seasonal migration and men's position within families. Comparative Migration Studies, 7, 2. https://doi.org/10.1186/s40878018-0106-2

Fiddian-Qasmiyeh, E. (2020). Introduction Recentering the south in studies of migration. Migration and Society: Advances in Research, 3, 1-18.

Fresnoza-Flot, A. (2017). Gender- and social class-based transnationalism of migrant Filipinas in binational unions. Journal of Ethnic and Migration Studies, 43(6), 885-901. 
Gallo, E., \& Scrinzi, F. (2019). Migrant masculinities in-between private and public spaces of reproductive labour: Asian porters in Rome. Gender, Place and Culture, 26(11), 1632-1653.

Gómez-Estern, B. M., \& de la Mata Benítez, M. L. (2013). Narratives of migration: Emotions and the interweaving of personal and cultural identity through narrative. Culture \& Psychology, 19(3), 348-368.

Grosfoguel, R., Oso, L., \& Christou, A. (2015). 'Racism', intersectionality and migration studies: Framing some theoretical reflections. Identities: Global Studies in Culture and Power, 22(6), $635-652$.

Grosswirth Kachtan, G. D. (2019). Challenging hegemonic masculinity by performance of ethnic habitus. Gender, Work and Organization, 26, 1489-1505.

Grundy, J., \& Smith, M. (2005). The politics of multiscalar citizenship: The case of lesbian and gay organizing in Canada. Citizenship Studies, 9(4), 389-404.

Hondagneu-Sotelo, P. (2017). Place, nature and masculinity in immigrant integration: Latino immigrant men in inner-city parks and community gardens. NORMA, 12(2), 112-126.

Hopkins, P. (2019). Social geography I: Intersectionality. Progress in Human Geography, 43(5), 937-947.

Janta, H., \& Christou, A. (2019). Hosting as social practice: Gendered insights into contemporary tourism Mobilities. Annals of Tourism Research, 74, 167-176.

Jonsson, S. (2020). A society which is not: Political emergence and migrant agency. Current Sociology. https://doi.org/10.1177/0011392119886863

Kanaiaupuni, S. (2000). Reframing the migration question: An analysis of men, women, and gender in Mexico. Social Forces, 78(4), 1311-1347.

King, R., \& Christou, A. (2010). Cultural geographies of counter-diasporic migration: Perspectives from the study of second-generation 'returnees' to Greece. Population, Space and Place, 15(2), $103-119$.

King, R., Mata-Codesal, D., \& Vullnetari, J. (2013). Migration, development, gender and the 'black box' of remittances: Comparative findings from Albania and Ecuador. Comparative Migration Studies, 1, 69.

Kofman, E. (1999). Female 'birds of passage' a decade later: Gender and immigration in the European Union. International Migration Review, 33(2), 269-299.

Kofman, E. (2004). Gendered global migrations. International Feminist Journal of Politics, 6(4), 643-665.

Kofman, E. (2019). Gendered mobilities and vulnerabilities: Refugee journeys to and in Europe. Journal of Ethnic and Migration Studies, 45(12), 2185-2199.

Kofman, E. (2020). Unequal internationalisation and the emergence of a new epistemic community: Gender and migration. Comparative Migration Studies. https://doi.org/10.1186/s40878-02000194-1

Kofman, E., Phizacklea, A., Raghuram, P., \& Sales, R. (2000). Gender and international migration in Europe: Employment, welfare, and politics. Routledge.

Lems, A., Oester, K., \& Strasser, S. (2020). Children of the crisis: Ethnographic perspectives on unaccompanied refugee youth in and en route to Europe. Journal of Ethnic and Migration Studies, 46(2), 315-335.

Lewis, R. (2013). Deportable subjects: Lesbians and political asylum. Feminist Formations, 25(2), 174-194.

Lewis, R. A., \& Naples, N. A. (2014). Introduction: Queer migration, asylum, and displacement. Sexualities, 17(8), 911-918.

Liversage, A. (2009). Vital conjunctures, shifting horizons: High-skilled female immigrants looking for work. Work, Employment and Society, 23(1), 120-141.

Luibhéid, E. (2018). Heteronormativity: A bridge between queer migration and critical trafficking studies. Women's Studies in Communication, 41(4), 305-309.

Mahler, S. J., \& Pessar, P. (2001). Gendered geographies of power: Analyzing gender across transnational spaces. Identities: Global Studies in Culture and Power, 7(4), 441-459. 
Manalansan, M. (2006). Queer intersections: Sexuality and gender in migration studies. International Migration Review, 40(1), 224-249.

Mole, R. C. M. (Ed.). (2021). Queer migration and asylum in Europe. UCL Press.

Morokvasic, M. (1984). Birds of passage are also women. The International Migration Review, $18(4), 886-907$.

Murray, D. A. (2014). The (not so) straight story: Queering migration narratives of sexual orientation and gendered identity refugee claimants. Sexualities, 17(4), 451-471.

Näre, L., \& Akhtar, P. (2014). Gendered mobilities and social change - An introduction to the special issue on gender, mobility and social change. Women's Studies International Forum, 47, 185-190.

Nawyn, S. J. (2010). Gender and migration: Integrating feminist theory into migration studies. Sociology Compass, 4(9), 749-765.

Noble, G. (2009). 'Countless acts of recognition': Young men, ethnicity and the messiness of identities in everyday life. Social \& Cultural Geography, 10(8), 875-891.

O'Neill, M., \& Harindranath, R. (2006). Theorising narratives of exile and belonging: The importance of biography and ethno-mimesis in 'understanding' asylum. Qualitative Sociology Review, II(I) Retrieved August, 2020 http://www.qualitativesociologyreview.org/ENG/archive_ eng.php

Oliver, C., \& O'Reilly, K. (2010). A Bourdieusian analysis of class and migration: Habitus and the individualising process. Sociology, 44(1), 49-66.

Parreñas, R. (2009). Inserting feminism in transnational migration studies. http:// lastradainternational.org/doc-center/2197/inserting-feminism-in-transnational-migrationstudies

Pasura, D., \& Christou, A. (2018). Theorizing Black African transnational masculinities. Men and Masculinities, 21(4), 521-546.

Phoenix, A., \& Bauer, E. (2012). Challenging gender practices: Intersectional narratives of sibling relations and parent-child engagements in transnational serial migration. European Journal of Women's Studies, 19(4), 490-504.

Pisarevskaya, A., Levy, N., Scholten, P., \& Jansen, J. (2019). Mapping migration studies: An empirical analysis of the coming of age of a research field. Migration Studies, 8(3), 455-481.

Silvey, R. (2004). Power, difference and mobility: Feminist advances in migration studies. Progress in Human Geography, 28(4), 490-506.

Stewart, A. (2015). Care or work: The tyranny of categories. In Care, migration and human rights: Law and practice (pp. 11-26). Routledge.

Szczepaniková, A. (2006). Migration as gendered and gendering process: A brief overview of the state of art and a suggestion for future directions in migration research. https://migrationonline. cz/en/e-library/migration-as-gendered-and-gendering-process-a-brief-overview-of-the-state-ofart-and-a-suggestion-for-future-directions-in. Last accessed 10 Feb 2020.

Vlase, I. (2018). Men's migration, adulthood, and the performance of masculinities. In I. Vlase \& B. Voicu (Eds.), Gender, family, and adaptation of migrants in Europe (pp. 195-225). Palgrave Macmillan.

Wang, C. (2016). Introduction: The 'material turn' in migration studies. Modern Languages Open. https://doi.org/10.3828/mlo.v0i0.88

Warren, A. (2016). Crafting masculinities. Gender, Place and Culture: A Journal of Feminist Geography, 23(1), 36-54.

Wernesjö, U. (2020). Across the threshold: Negotiations of deservingness among unaccompanied young refugees in Sweden. Journal of Ethnic and Migration Studies, 46(2), 389-404.

Wimmer, A., \& Glick Schiller, N. (2002). Methodological nationalism and beyond: Nation-state building, migration and the social sciences. Global Networks, 2(4), 301-334.

Wimmer, A., \& Glick Schiller, N. (2003). Methodological nationalism, the social sciences and the study of migration: An essay in historical epistemology. International Migration Review, 37(3), 576-610. 
Wojnicka, K., \& Pustułka, P. (2019). Research on men, masculinities and migration: Past, present and future. NORMA, 14(2), 91-95.

Xiang, B. (2016). Beyond methodological nationalism and epistemological behaviouralism: Drawing illustrations from migrations within and from China. Population, Space and Place, 22, 669-680. https://doi.org/10.1002/psp.v22.7

Zapata-Barrero, R. (2019). Methodological interculturalism: Breaking down epistemological barriers around diversity management. Ethnic and Racial Studies, 42(3), 346-356.

Zhu, H., \& Qian, J. (2020). New theoretical dialogues on migration in China: Introduction to the special issue. Journal of Ethnic and Migration Studies. https://doi.org/10.1080/1369183X.2020. 1739372

Open Access This chapter is licensed under the terms of the Creative Commons Attribution 4.0 International License (http://creativecommons.org/licenses/by/4.0/), which permits use, sharing, adaptation, distribution and reproduction in any medium or format, as long as you give appropriate credit to the original author(s) and the source, provide a link to the Creative Commons license and indicate if changes were made.

The images or other third party material in this chapter are included in the chapter's Creative Commons license, unless indicated otherwise in a credit line to the material. If material is not included in the chapter's Creative Commons license and your intended use is not permitted by statutory regulation or exceeds the permitted use, you will need to obtain permission directly from the copyright holder. 